\title{
Erratum to: Culture and Communication in Thailand
}

\author{
Patchanee Malikhao
}

\section{Erratum to:}

P. Malikhao, Culture and Communication in Thailand, Communication, Culture and Change in Asia, DOI 10.1007/978-981-10-4125-9

The original version of the book was inadvertently published without implementing the special instruction to include the author names 'Jan Servaes', 'Fiona Servaes' and 'Lisa Servaes' in Chapters 4, 8 and 9, respectively, which have to be now included. The erratum book has been updated with the changes.

The updated original online version of this book can be found at https://doi.org/10.1007/978-981-10-4125-9_4

https://doi.org/10.1007/978-981-10-4125-9_8

https://doi.org/10.1007/978-981-10-4125-9_9 